Clinical Social Work Journal

Vol. 16, No. 3, Fall 1988

\title{
THE TREATMENT OF BULIMIA FROM A SELF PSYCHOLOGICAL PERSPECTIVE
}

\author{
F. Diane Barth, M.S.W., C.S.W., A.C.S.W.
}

ABSTRACT: This paper examines concepts from self psychology which contribute to the understanding of bulimia. A case example from the author's work illustrates the significance of the sense of self both in the development of bulimic symptoms and also in the therapeutic process. Painful feelings of shame and humiliation over "who and what one is" are often part of the bulimic experience. The author suggests that therapist's role is not so much to "change" the bulimic person, but to accept and understand who the person is and how he or she came to be that way. Change often follows such understanding.

With the prevalence of bulimia in the female population today, it has become more important than ever to understand the dynamics of the disorder and the types of interventions which are most useful in its treatment. Although much has been written about the etiology of bulimia, there is no definitive answer to the question of why people become bulimic. Theorists have cited various possible causes, such as difficulty separating from mother (Chernin, 1985) and other pathological family dynamics (Jones, 1985; Minuchin, Rosman, \& Baker, 1978; Wilson, 1983), sociocultural factors (Orbach, 1978), and diverse intrapsychic issues (Wilson, 1983). It may be productive to follow Palombo's (1985) recommendation to the clinician working with depressed clients. He suggests that the therapist explore "the nature of the [individual's] experience" instead of attempting to make "generalizations about the intrapsychic states" derived from "the external events or circumstances that create the condition ..." (p.33).

In my work with bulimic women, I have found that many of their experiences involve "self" issues, such as attempts to maintain selfesteem and self-cohension. However, while Goodsitt (1977) and Geist (1984) have written about narcissistic issues in anorexic women, few have written about them in bulimic women (see Jones, 1985). 
In this paper I will examine some of the ways a self psychological perspective can contribute to a therapist's understanding of and work with patients with bulimia. Utilizing the example of a young woman who was in therapy with me and whose symptoms and dynamics are in many ways typical of other bulimic women with whom I have worked, I will illustrate the importance of understanding the many connections between self-esteem, self-cohesion, and bulimic symptoms.

Self psychology alone cannot explain all dynamics of all women with bulimia, but in conjunction with other theories it offers the therapist a helpful perspective for understanding and treating many of these women.

There are four major areas from self psychology which I believe can contribute significantly to a therapist's work with this population. These are: (1) the focus on self-esteem and self-cohesion as basic needs of all human beings; (2) the view of symptoms as attempts to restore and/or maintain self-esteem and self-cohesion; (3) the use of empathy as a primary therapeutic tool; and (4) the concept of the selfobject.

Let me briefly review these concepts. I will then further elaborate on their implications for therapy with individuals with bulimia in the context of the clinical vignette.

1. Stolorow and Lachmann (1980) tell us that it is human nature to strive for self-esteem and for a cohesive, stable sense of self over time and across stressful situations. Many individuals with bulimia have neither a stable sense of self nor a sense of self-esteem. The bulimic symptoms help to alleviate feelings of fragmentation, disorganization, confusion, and self-hatred, while at the same time confirming a stable, if negative, sense of self. As one woman poignantly put it, "It's better to hate yourself than not to have a self at all."

2. It is a logical next step to think of symptoms as part of an effort to organize the self and/or maintain self-esteem (Kohut, 1971; Ornstein \& Ornstein, 1980; Tolpin, 1983). Bulimic symptoms may be utilized, for example, to soothe painful and unacceptable feelings or to adapt to an environment in which the self is constantly subjected to painful and/or damaging experiences. As Hartmann (1958) has shown us, symptoms are not simply evidence of psychopathology but are also often evidence of an adaptive response to a maladaptive environment. While bulimic behavior may seem maladaptive to an outside observer and may indeed cause the individual pain, it is also a highly successful method for protecting a damaged self in a frightening world.

3. Kohut and his followers did not invent the concept of empathy as a psychotherapeutic tool, (they were preceded by Freud 1916-17, Jacobson (1964), and Winnicott (1965) to name only a few). But they have emphasized the importance of the therapist's ability to understand the patient's experience from the patient's point of view. The therapist's 
empathy is often a novel experience for many individuals with bulimia, who have never before felt that someone else was actively attempting to understand their perspective. Furthermore, people with bulimia are often highly critical of their own feelings and thoughts and therefore unable to empathize with themselves. Part of the therapeutic work involves an identification with the therapist's empathic stance, and the subsequent development of empathy for their own feelings and needs. Such "self" empathy is necessary before the feelings can be iniegrated into the individual's overall sense of self.

4. The patient's ability to utilize the therapist's attitude towards him or herself is part of a selfobject transference. Kohut (1971) defines a selfobject as a person or an object which fulfills certain needs for an individual which the individual cannot provide for him or herself. These needs may be in the realm of self-esteem regulation, that is, those actions or behaviors which increase or decrease a person's self-esteem, or they may be in the more general realm of self-regulation-for example, helping the person to place limits on his or her feelings and/or actions. For many people with bulimia, unable to soothe themselves in other ways, and unable to trust others to provide selfobject functions (Ornstein, 1974), the bulimic behavior, rather than another person, fulfills some of these functions.

Today most psychotherapists would agree with Waelder (1936) that symptoms have multiple meanings or functions. Not only can the same symptom have different meanings for different individuals, but the same symptom can also have different meanings for the same individual at different times. It is therefore important for a therapist to try to understand the meaning a symptom has for a specific individual at a specific moment without imposing an "experience-distant" theoretical stance on the client's experience.

Eating disorders are complicated, complex disorders which require the therapist's patience and willingness to explore many possible dynamics before they even begin to respond to therapy. Understanding the importance of the symptoms in the maintenance of self-esteem and selfcohesion can help the therapist to have patience with stubborn, recalcitrant symptoms and to understand why simply making unconscious fears and fantasies conscious is not enough to lead to change in this population.

A clinical example will illustrate the way this approach affects the therapeutic process. Patricia (not her real name) entered therapy with me shortly after she graduated from college. She was living at home and working part-time at a job which her father had helped her to find and which she wanted desperately to leave. She also wanted to move out of her parents' home, to find a career direction, and to improve her relationships with men. 
She had never had a long-term relationship, but she had always had a boyfriend when she wanted one. She had several women friends to whom she turned for "support and sustenance." As she described her women friends and her current and past boyfriends, it seemed to me that the men were interchangeable with one another, as were the women. Although she needed each sex for very specific functions, $\mathbf{P a}$ tricia did not seem to differentiate between one woman and another, or one man and another.

What she required was women who "understood" her, by which she meant had the same feelings about things as she did, and men who found her attractive, liked her sexually, and enhanced her self-esteem in ways her women friends could not. It was also necessary that she admire the men, something she did not need or expect to feel for women friends.

In her descriptions of an almost compulsive need for sex which paralleled her compulsive need for huge amounts of food, I heard a panicky sense of not knowing who she was or where she began or ended, either physically or psychologically. It would have been easy to hear both behaviors as derivatives of unconscious and unacceptable drives, as some theorists do. I chose instead to follow a self psychological approach in which I explored with Patricia the meaning of the apparent drives. From this perspective, the symptoms appeared to be attempts to soothe hurt and angry feelings resulting from damage to self-esteem. The compulsive binging, purging, and sexual activity seemed to me to be an attempt on Patricia's part to restore her self-esteem and sense of continuity rather than a defense against instinctual drives. At any rate, looking at the bulimia as a drive derivative would not have helped Patricia to understand the purpose the behaviors served for her. And there was no question in my mind that for Patricia, as for other women with bulimia, they did serve a purpose.

Patricia did not know that I worked with people with eating disorders when she began therapy with me. It was several weeks before she shared the information that she had bulimia, although I was not surprised when she did tell me. At that point I asked her, as I do with most individuals with bulimia, to begin to pay attention to what she was doing, where she was, and what she was thinking about at the moment she began to plan her next binge.

We soon began to notice that her compulsive binges and purges (Patricia was a vomiting bulimic) and her nearly overwhelming sexual desires were often triggered by a feeling that someone upon whom she counted for understanding and support had let her down, disappointed her somehow. This was true in her relationships with friends, co-workers, her parents, her boyfriends, and, we soon found, with me. As individuals we all seemed interchangeable, noticeable to Patricia only in 
CLINICAL SOCIAL WORK JOURNAL

terms of whether or not we met certain needs which she could not meet for herself. The need for understanding and support from others was central for Patricia. The people to whom she turned for this understanding functioned as selfobjects for her.

For Patricia, "understanding" her meant actually experiencing what she experienced, because, as she explained to me, unless her selfobject felt what she felt, she could not feel it herself.

Kohut initially described two forms of selfobject transference-the idealizing transference and the grandiose or mirror transference. Later (1984) he described a third, the twinship or alter-ego transference. Stolorow (1986) and Basch (1986), have suggested that there are other forms of selfobject transferences. Patricia's selfobjects were in part mirroring selfobjects, in part twinship or alter-ego selfobjects, and in part something else, something perhaps a little more primitive, in that it was a little less separate from her sense of self than an idealized, mirroring, or twinship selfobject.

Stolorow (1986) points out that the selfobject experience is an intrapsychic rather than interpersonal one. The selfobject may be experienced as a separate object, but the function provided by the selfobject is experienced intrapsychically. This means that a selfobject failure may not necessarily be an objective failure. Yet the therapist who points out the "reality" of the experience will lose the opportunity to deepen the process of understanding which is a major component of psychotherapy.

It gradually became apparent that Patricia's craving for food and sex, her binging and vomiting cycles, and her almost delusional bodily sensations of growing and shrinking were often directly related to episodes of feeling misunderstood or not understood by her selfobjects. This became evident in the transference when we began to explore what she experienced as my empathic failure-that is, my failure to function as a validating and confirming selfobject.

As do many people with bulimia, Patricia had an almost physical response when she felt disappointed by me. Although she could not articulate her feelings at the moment, I had immediate cues that something had gone wrong. Her face, usually open in an almost childlike way, became closed and stony, and her speech, usually organized, although dramatic, became rambling and disorganized.

The first few times this occurred, I asked Patricia what had happened. She was unaware that anything had changed in either her manner or her feeling state. I pointed out the changes in her facial expression and her speech, but I did not press the matter, since she was clearly not ready to make such differentiations. I hypothesized that she was either afraid to do so, perhaps because to do so would threaten our relationship in some way, or else because she was actually unable to recog- 
nize such changes in her self-state-both of which are frequent dynamics in this population.

I watched for the next opportunity to observe the behavior with the hope of beginning to understand - at least for myself-what triggered it. It appeared to be the kind of loss of cohesion described by Kohut $(1971,1977,1984)$ as a response to an empathic failure on the part of a selfobject. I was therefore on the lookout for this reaction in response to some of my interventions.

One day Patricia began to speak of feeling as though she lived in a glass house. She could see other people, and they could see her, but she could not touch them or be touched by them. I said that I understood (which I did, as it seemed to perfectly describe what occurred in the therapy). I asked her if she thought this ever happened in our sessions. She looked surprised and thoughtful, then nodded. "Is that what you meant when you said I seemed to pull away the other day?"

She now seemed ready to look at this subject. I thought I would risk adding to the experience with my own imagery, although I was aware that at times patients can experience such additional input from the therapist as an empathic failure (Kohut, 1971). I told her that yes, it was what I had meant, but that my experience of it at those times was as though she was behind a mattress rather than a glass wall. I could hear her, but not clearly, and I could not see her, metaphorically speaking, at all.

She loved the metaphor, felt deeply understood by me, and actually began to have some awareness of the way she pulled away from me when she felt I did not understand her. This seemed to pave the way for us to look at moments when she did pull away, which in turn led to an exploration of what she felt when I failed her. There were many moments of failure, but now we had a metaphor with which to describe her reaction, and she began to recognize it herself when it happened. We now had the necessary base of noncritical self-awareness which allowed us to begin to explore what triggered her withdrawal from me.

Only if the therapist can accept that the patient must resist in order to protect the integrity of a fragile and vulnerable self can the patient eventually enter into the therapeutic alliance and make use of the therapist as a selfobject. This is a divergence from classical theory, in which resistance is seen as maladaptive, to be analyzed and overcome. From a self psychological point of view, the resistance, what A. Ornstein (197.4) calls the dread to repeat, is perhaps the only method the individual has at his or her command to protect self-esteem and self-cohesion.

Patricia could not ally herself with me enough to explore her feelings with me until she repeatedly experienced my noncritical acceptance of her need to withdraw from me. I encouraged her to look for in- 
CLINICAL SOCIAL WORK JOURNAL

ner clues which would signal that she was withdrawing. She was very tuned into her own physical responses-feeling big, small, fat, growing, disappearing. I asked her to tell me as much as she could about her physical experiences at the moment that I sensed her withdrawal. As she did so, she began to realize that she felt criticized by me. We soon learned that each time my perspective was different from hers, she felt criticized, diminished, and lost a sense of who she was. Recognition of this chain of events and of her fear that I wanted her to be just like me, not a person in her own right, was generally enough to help her reorganize.

Throughout his writings, Kohut maintains that it is the process of empathic rupture and healing which embodies the therapeutic work and leads to what he calls transmuting internalization and change. In his last book (1984), he divides the therapeutic work into two parts - understanding, and explaining, or interpreting what one understands. Kohut suggests that with some patients, the entire work is done in the understanding phase. Although I think that the explaining phase can often go hand in glove with the understanding phase, it is an extremely important concept for the therapist working with bulimic patients, many of whom have never been understood or accepted for themselves and who do not understand or accept themselves as a result.

For many of these people, the therapist becomes an empathic selfobject who accepts unacceptable aspects of themselves (including the eating behavior), names unnameable feelings, and makes it safe to look at what G. Klein (1976) calls split-off self schema. As one bulimic woman said to me, "It's as if there were all these closed doors inside me. Doors that I was afraid to open, for fear of what might come out. With you, I've opened some of them. It's been okay, because I knew you'd let me close them if I needed to-even help me, if I couldn't do it myselfand that you'd help me sort through what I found in there, if I wanted to. Now I can open and close them myself. I feel more complete, more whole, more connected to myself."

As Gedo (1979) suggests, it is sometimes important to help patients set limits on their feelings when they cannot do it themselves. For people with bulimia, this may mean helping them to "close doors," to recognize when their anxiety is escalating to what may become intolerable dimensions, and to help them calm down and even temporarily suppress certain thoughts and feelings so that they do not need to binge and purge to soothe themselves.

Patricia was unable to utilize the explaining, or interpreting, component of therapy for some time. She was struggling simply to allow herself to know what she felt. It was confusing to her to try to understand it in the context of earlier experiences, which she remembered only as also muddled or confused. 
Yet there was plenty of opportunity for disruption and healing in our relationship and for "transmuting internalization," or what Ruth Gruenthal (unpublished) explains in the following way.

The patient's experience of the analyst's understanding responsiveness, expressed in the form of the interpretive sequence [of understanding and explaining], is seen as changing the patient's experience of the analyst's empathic failure from a traumatic threat to his sense of self-integrity into a more optimal experience, allowing the progressive integration of the patient's sense of self. (pp.17-18)

Each time we explored something she experienced as an empathic failure on my part, Patricia became more comfortable recognizing her own needs and feelings and modulating them by talking about them and asking for what she needed from me rather than by binging on food and/or sex and then feeling worse than before about herself. As she found herself able to discuss her needs with me, and to find ways of getting those needs met (sometimes simply discussing her needs met them), her self-esteem increased, her ability to tolerate not always getting her needs met increased, and her binging and purging decreased gradually.

After nine months in therapy, Patricia moved out of her parents' home and began a job which she found herself and which, although she hated, was the first full-time job she had ever held for longer than a month. She also began a relationship with a man who, for the first time in her experience, "actually meets my needs!"

When things began to deteriorate between herself and this man, I made a comment in an attempt to help her maintain the relationship. I realized later that this was out of my countertransferential need, not out of a response to her needs.

I was concerned that she was about to sabotage the best relationship she had ever been in, and I was eager to make an interpretation which would keep her from repeating destructive patterns of relating to men. As a result of the work we did following the empathic rupture which my remark caused, Patricia and I understood that my implicit expectations of changing her (not uncommon for therapists) paradoxically interfered with her ability to change. It was not my attempt to change her which would, in the end, help Patricia to grow, but instead my acceptance of who she was and my recognition of why she was that way which would foster her development.

In the session after my "interpretation," Patricia began a lengthy description of a binge-purge cycle which, she said, was preceded by hysterical sobbing and a powerful need for sex. I asked what had occurred prior to the crying. She described an incident with her boyfriend, in which she felt furious that he had not understood that she needed his 
CLINICAL SOCIAL WORK JOURNAL

attention and then immediately felt guilty and selfish for being so demanding. She then looked at me expectantly.

My intervention in the prior session had been in the form of a suggestion that she might feel better if she could see things from her boyfriend's point of view. I now asked if she was afraid I was going to criticize her for not being more sympathetic to his needs? She began to cry. I asked her to try to tell me about her thoughts at the moment. Through her tears, she said that she was ashamed to be so selfish, that she was ashamed not to be able to see his side, but the problem was, she said, that she just couldn't see him as having needs at all-and not only that, she needed to see him as not having needs. She needed him to be strong and invulnerable, she said, so that he could take care of her (one aspect of Kohut's idealized selfobject). "I know it's selfish," she sobbed. "I just can't help it."

I nodded and said quietly, "I can understand that now. It's as though I was asking someone who was starving to share their small crust of bread with someone else. You can't give to someone else unless you feel you have something to give."

I could almost see the structure-building activity of this process. Patricia visibly pulled herself together. I could see that she now felt solid again, an impression which she herself confirmed. Moreover, the next time she felt misunderstood or criticized by me, instead of binging and purging immediately, she was able to let me know that she was feeling inadequate and we quickly pinpointed the blow to her selfesteem caused by something I had said.

We came to understand her binging, purging, and promiscuous sexual activity as an attempt to soothe herself when she felt hurt, inadequate, and misunderstood, as well as when she felt ashamed of something she had revealed to me. She now had a new kind of knowledge about herself. One of her doors was open. This self-awareness did not, in and of itself, lead to change in her symptoms or personality. It was something which we re-experienced many times in the course of our work together, but each time, it seemed easier to discover what had caused the dissolution of her sense of herself, or the damage to her selfesteem, and gradually she turned less and less to her bulimic symptoms as an automatic means of soothing herself.

Kohut believed that people never stop needing selfobjects. In his last book (1984), he suggests that analysis cures people by helping them to learn to find appropriate selfobjects and to use them appropriately. Again, Ruth Gruenthal (unpublished) has expanded upon this idea:

. . . self psychology sees the analyst's interpretive activity, experienced as selfobject function, as aiding the transformation of the patient's archaic selfobject transference into a more mature selfobject 
bond. The patient's selfobject relatedness changes qualitatively along its own developmental line. As archaic selfobject transference forms are transformed into more mature selfobject relatedness, concomitant repeated and cumulative alterations in the patient's self become enduring patterns. (p.18)

The changes in Patricia's relationship with me gradually led to changes in her experience of herself, to the building of a stronger, more stable sense of herself, and thence to changes in her relationships with others. Only as a complex series of changes occurred in her self-perception and in her interactions with others was she able to stop utilizing binging and vomiting to maintain a sense of wholeness and autonomy.

Still, a large portion of her sense of self is dependent on others, and still, under crisis, she returns to the soothing mechanism of binging, vomiting, and sexual activity. Many therapists working with a bulimic individual become concerned over the linked issues of regression-in this case, return to symptoms-and resistance. From a self psychological perspective, many people with bulimia have a fragile, vulnerable sense of self and need tools with which to pull themselves together after a narcissistic injury or other damage to self-esteem. Bulimia is a highly successful tool. Because it can only be dispensed with when there are other, effective selfobjects available, or when the individual has a strong enough sense of self to withstand blows to self-esteem without losing all good feelings about him or herself, it is not easy to change. A self psychological perspective makes it easier for a therapist to handle some of the difficulties inherent in treating bulimic patients (Jones, 1985), including what at times may appear to be a resistance to the therapist or the therapy.

Patients themselves let us know if our approach is working. In a recent session, Patricia confirmed the value of a self psychological approach to my work with her. She began the session by saying that she did not know what to talk about, because everything was fine, and she felt that she should talk about problems in therapy. She went on to tell me several examples of feeling more "in herself" as she put it. She was reading a novel, something she could not remember doing before except when it was required in school, and she was enjoying it. She was writing a short story, something she had attempted many times before, but which she never completed.

And she had recently had a fascinating conversation with the boyfriend of the empathic failure described above. He was no longer a lover, but simply a friend. "He told me he wasn't crazy about his job," she told me with glee. I asked about the gleeful emotion.

"Well, I'm glad to know he has needs. It makes him more human. But at the same time, it frightens me." 
CLINICAL SOCIAL WORK JOURNAL

"Why do you think it frightens you?" I wondered.

"Because I need him to be strong, stable ..."

"Do you know why that is?" I asked.

"Because I'm not."

I asked her to try to put into words why his being strong and stable was important-how it contrasted with her not being that way. It took the rest of the session, but she was able to articulate her belief that women are volatile, hysterical, and incompetent, and need men to be strong and hold them together. She was beginning to think that she could be competent and feel good about herself without a man's approval, and, to her surprise, she was feeling closer than ever before to some of the men in her life.

She told me, "I was always afraid that if I didn't need them, they wouldn't have any reason to connect with me, but I was always afraid that they wouldn't meet my needs, anyway. I think they like me more when I'm more competent and self-confident-but I still don't trust them to meet my needs."

Patricia, like many bulimics, continues to binge and purge at times of stress, but now she can often figure out why she did so, and she no longer experiences the degree of self-hatred which used to increase the need to binge and purge, reinforcing a vicious cycle. Now, if she is unable to stop a binge-purge cycle, she is more accepting of herself, and does not further the punishment by continuing to binge and purge.

Patricia has developed some empathy for herself. She has begun to allow herself to feel what she feels, to think what she thinks, and to be who she is, without having to change herself in some way to make herself more "acceptable" or "likeable." This is perhaps one of the most important contributions of self psychology to the therapeutic work with individuals with bulimia. While different people with bulimia have different dynamics and different needs, the possibility for many of them is that, in some way, and to some extent, the bulimia includes an attempt to repair damage to the sense of self. From this perspective, one goal of therapy may well be to help people to recognize who they are and to accept themselves fully, with all of their own characteristics- "good" and "bad." With such self-acceptance, change is often spontaneous.

\section{REFERENCES}

Basch, M.F. (1986). How does analysis cure?: An appreciation. Psychoanalytic Inquiry, 6(3), 403-428.

Chernin, K. (1985). The hungry self. Women, eating and identity. New York: Harper \& Row.

Freud, S. (1916-1917). Introductory lectures on psychoanalysis, S.E. 15-16. London: Hogarth Press, 1986. 
F. DIANE BARTH

Gedo, J. (1979). Beyond interpretation: Towards a revised theory for psychoanalysis. New York: International Universities Press.

Geist, R. (1984). Therapeutic dilemmas in the treatment of anorexia nervosa: A self psychological perspective. Contemporary Psychotherapy Review, 2, 115-142.

Goodsitt, A. (1977). Narcissistic disturbances in anorexia nervosa. Annuals of Adolescent Psychiatry, 5, 304-312.

Gruenthal, R. (Unpublished). From a panel discussion on different psychoanalytic theories.

Hartmann, H. (1958). Ego psychology and the problem of adaptation. New York: International Universities Press.

Jacobson, E. (1964). The self and the object world. New York: International Universities Press.

Jones, D. (1985). Bulimia: A false self-identity. Clinical Social Work Journal, 13(4), 305316.

Klein, G. (1976). Psychoanalytic theory. New York: International Universities Press.

Kohut, H. (1971). The analysis of the self. New York: International Universities Press.

Kohut, H. (1977). The restoration of the self. New York: International Universities Press.

Kohut, H. (1984). How does analysis cure? Chicago: University of Chicago Press.

Minuchin, S., Rosman, B.L., \& Baker, L. (1978). Psychosomatic families: Anorexia nervasa in context. Cambridge, Mass: Harvard University Press.

Orbach, S. (1978). Fat is a feminist issue. New York: Berkeley Publishing Company.

Ornstein, A. (1974). The dread to repeat and the new beginning: A contribution to the psychoanalysis of the narcissistic personality disorders. The Annual of Psychoanalysis,
231-248.

Ornstein, P., \& Ornstein, A. (1980). Self psychology and the process of regression. Psychoanalytic Inquiry, 1, 81-105.

Palombo, J. (1985). Depletion states and selfobject disorders. Clinical Social Work Journal, 13(1), 32-49.

Schafer, R. (1983). The analytic attitude. New York: Basic Books.

Stolorow, R. (1986). Critical reflections of the theory of self psychology: An inside view. Psychoanalytic Inquiry, 6(3), 387-402.

Stolorow, R., \& Lachmann, F. (1980). The psychoanalysis of developmental arrests. New York: International Universities Press.

Tolpin, P. (1983). A change in the self: The development and transformation of an idealizing transference. International Journal of Psychoanalysis, 64, 461-483.

Waelder, R. (1936). The principle of multiple function: Observations on overdetermination. Psychoanalytic Quarterly, 5, 45-62.

Wilson, C.P., (Ed.) (1983). Fear of being fat: The treatment of anorexia nervosa and bulimia, New York: Jason Aronson, pp.29-47.

Winnicott, D.W. (1965). The maturational processes and the facilitating environment. New York: International Universities Press.

102 West 85th Street \#5H

New York, NY 10024 
Copyright of Clinical Social Work Journal is the property of Springer Science \& Business Media B.V. and its content may not be copied or emailed to multiple sites or posted to a listserv without the copyright holder's express written permission. However, users may print, download, or email articles for individual use. 